\title{
Health Maintenance Practices among Nurses of a Tertiary Level Hospital of Nepal
}

\author{
Shovana Shrestha, ${ }^{1}$ Aastha Singh Thakuri, ${ }^{1}$ Rashmi Devkota ${ }^{1}$ \\ ${ }^{1}$ Department of Nursing, Nepal Medical College, Kathmandu, Nepal.
}

\begin{abstract}
Background: Health maintenance practices are those activities that preserve a person's current state of health and that prevents future diseases or injuries from occurring. Nurses represent an important part of the hospital workforce and serve as role models when caring for patients. A healthy nurse can deliver quality care to the patients to the optimal level. However, there are no studies that explored the health maintenance practices among nurses, here in Nepal. This study was therefore conducted to assess the health maintenance practices among nurses. Materials and Methods: A total of 197 out of 208 nurses from Nepal Medical College Teaching Hospital (NMCTH) were enrolled in the study using purposive sampling method. Pretested questionnaire was used as a tool for data collection. SPSS version 16 was applied for data entry and analysis. Descriptive statistics (Percentage, frequency, mean, standard deviation) were used for data analysis. Results: Among 208 nurses only 197 responded yielding a response rate of $94.7 \%$. The findings suggest that nurses did not have a good screening, dietary, exercise and vaccination practices. Lack of time, work overload, psychological stress from work were the main barriers pointed out by the nurses that hinder them to maintain their health status. Conclusion: Nurses did not have good health maintenance practices which could directly influence on the quality of care they provided. Thus it is very necessary to initiate program that promotes health of nurses.
\end{abstract}

Keywords: health maintenance practice; Nepal; nurses; self care.

\section{INTRODUCTION}

Health maintenance practices are those activities that individuals initiate and exercise on their own behalf in maintaining life, health and wellbeing ${ }^{1}$ These activities not only helps in maintaining the health but also assists in preventing future diseases from occurring. ${ }^{1}$ Nurses are accounted as potential health advocate; and are considered as the role model for the patients. ${ }^{2}$ However, the message and information that nurses advocate will be undervalued, if they themselves cannot replicate that into their action ${ }^{3}$ Therefore, it is equally necessary that nurses engage themselves in self- care activities so as to maintain their health status at optimal level.

The American Nurses Association has defined a healthy nurse as " one who actively focuses on creating and maintaining a balance and collaboration of physical, intellectual, emotional, social, spiritual, personal and professional wellbeing". 4 Thus, maintaining nurses own health is an essential component to represent them as a role model so that they can deliver quality of care. Nurses' health status can be determined by their nutritional status, sleep/ exercise pattern, BMI, stress level, regular physical checkup, screening and immunization status. ${ }^{5}$ All these parameters are required to maintain optimal body function and to be more productive. ${ }^{6}$

Nurses who indulge themselves in self-care activities are in a condition to deliver high quality care to their patients. However, there is need to address several lacunae which might have limited nurses from caring themselves. Short staffing, increased overtime, increased report of psychological stress, burnout, work shift demands, poor nutrition, lack of exercise and absenteeism have been significant factors that are hindering nurses to maintain their optimal health. ${ }^{6}$

The quality of the care provided, the knowledge and skills of nurses regarding patient care are routinely assessed but the condition of the care provider (nurses) has not gained much attention. ${ }^{4}$ In Nepal, the situation is even worse as there seemed to be no studies conducted focusing this aspect to the best of our knowledge. Nurses being such a

Correspondence: Ms. Shovana Shrestha, Department of Nursing, Nepal Medical College, Kathmandu, Nepal. Email: shovana35@gmail.com. DOI: 10.3126/jcmsn.v14i2.19126. ORCID ID: orcid.org/0000-00024708-6628. Article received: 2018-02-02. Article accepted: 2018-05-28. 
vital part of health care team, assessing their health are of paramount importance as it directly influences quality patient care. Hence, to shed light on this aspect this study was conducted to assess the health maintenance practice among nurses.

\section{MATERIALS AND METHODS}

A descriptive cross-sectional design was employed to collect the data from 208 nurses of Nepal Medical College and Teaching Hospital (NMCTH), using purposive sampling technique. This study was approved by the Institutional Review Committee of Nepal Medical College. Further, verbal consent was obtained from the participants. Participants not willing to participate and absent at the time of data collection were excluded. Data collection was done for a period of one month in the month of February, 2016 AD.

A semi structured questionnaire was formulated based on the guidelines given by American Heart Association, ${ }^{6}$ World Health Organization (WHO) guidelines on Body Mass Index, ${ }^{7}$ Centre for Disease Control, ${ }^{8}$ American Cancer Society, ${ }^{9}$ WHO global strategy on diet, physical activity and health ${ }^{10}$ and consultation with experts. Further, it was pretested among $10 \%$ of the total sample population among nurses of another tertiary level hospital. Self-administered questionnaire was used intending to collect data on general information of respondents, their screening practices (general physical checkup, Breast Self-Examination (BSE), Mammography, Pap smear), vaccination practices, habits (alcohol consumption and smoking habit), dietary, exercise and rest pattern. Data were entered and analyzed in SPSS version 16.0. Frequency, percentage, mean and standard deviation were obtained from the data.

\section{RESULTS}

A total of 197 nurses out of 208 participated in the study indicating the response rate of $94.71 \%$. More than two third $(74.1 \%)$ of the nurses fall under the age cohort of 20-29 years (Table 1). Married and unmarried participants were nearly equal in number. One third $(65.5 \%)$ of the nurses had qualification up to PCL level and majority (86.3\%) of the nurses hold the position of staff nurse. More than two third $(79.2 \%)$ had work experience of more than one year. The Body Mass Index (BMI) Classified as per the criteria given by World Health Organization $^{7}$ for Asian population revealed that more than half $(61.4 \%)$ were overweight, while only one third $(36.5 \%)$ had healthy weight. The data stresses that the major reported health problem of nurses was backache $(66.03 \%)$ followed by hypertension (18.80\%), migraine (7.54\%) while the least was asthma (1.88\%) (Table 1).

\begin{tabular}{|c|c|}
\hline \multicolumn{2}{|c|}{ Age of respondents (Completed in Years) $(n=197)$} \\
\hline Below 20 & $13(6.6)$ \\
\hline $20-29$ & $146(74.1)$ \\
\hline $30-39$ & $26(13.2)$ \\
\hline$\geq 40$ & $12(6.1)$ \\
\hline \multicolumn{2}{|c|}{$\begin{array}{l}\text { Mean age } \pm S D=26.61 \pm 8.10 \text { Age Range: } 17 \\
\text { to } 69 \text { years }\end{array}$} \\
\hline \multicolumn{2}{|c|}{ Marital Status of respondents $(n=197)$} \\
\hline Married & $100(50.8)$ \\
\hline Unmarried & $97(49.2)$ \\
\hline \multicolumn{2}{|c|}{ Level of Education $(n=197)$} \\
\hline PCL Nursing & $129(65.5)$ \\
\hline Bachelor in Nursing & $68(34.5)$ \\
\hline \multicolumn{2}{|c|}{ Post of Respondents ( $n=197)$} \\
\hline Nurse In charge & $16(8.1)$ \\
\hline Senior Staff Nurse & $11(5.6)$ \\
\hline Staff Nurse & $170(86.3)$ \\
\hline \multicolumn{2}{|c|}{ Work Experience $(n=197)$} \\
\hline$\leq 1$ year & $41(20.8)$ \\
\hline$>$ 1years & $156(79.2)$ \\
\hline \multicolumn{2}{|c|}{ BMI of Respondents $(n=197)$} \\
\hline Underweight & $4(2.0)$ \\
\hline Normal & $72(36.5)$ \\
\hline Overweight & $121(61.4)$ \\
\hline \multicolumn{2}{|c|}{ Mean $\mathrm{BMI} \pm \mathrm{SD}=25.44 \pm 12.28$} \\
\hline \multicolumn{2}{|c|}{ Health Problems of Respondents $(n=53)$} \\
\hline Backache & $35(66.03)$ \\
\hline Hypertension & $10(18.80)$ \\
\hline Migraine & $4(7.54)$ \\
\hline Hypothyroidism & $3(5.66)$ \\
\hline Asthma & $1(1.88)$ \\
\hline
\end{tabular}

Regarding the health maintenance practices, nearly half of the respondents $(47.7 \%)$ reported that they do regular annual physical checkup. Of the total 189 premenopausal participants, only $52.92 \%$ were found to perform Breast Self- Examination (BSE) 5 -7 days after menstruation each month. While, none of the menopausal participants $(n=8)$ were found to perform BSE. Only, three Participants (25\%) out of 12 who were of age group 40 and above were found to perform mammography annually. Similarly, regular Pap smear (every three years) was found to be done by only three $(1.71 \%)$ out of total 175 eligible participants. Of the total 197 nurses, only $1.5 \%, 47.2 \%$ and $63.5 \%$ had vaccination against Influenza, tetanus toxoid and hepatitis B respectively (Table 2). 
Smoking habit was reported by none of the nurses while alcohol consumption habit was reported by $154(78.2 \%)$ nurses. All the nurses who reported that they consumed alcohol were social drinkers. The dietary pattern of nurses suggests that, only $37.1 \%$ of respondents consumed diet low in saturated fat and cholesterol every day. The dietary pattern that was followed routinely by relatively significant number of participants were: having at least 8 glasses of water each day $(57.9 \%)$ and eating lots of vegetables (59.4\%). Only $25.9 \%$ of participants were found to perform 30 minute exercise 5 times per week. While $66.0 \%$ were found to take enough sleep of 6-8 hours per day (Table 2).

More than two-third (81.21\%) of respondents agreed that the barriers to their health maintenance practice were lack of time due to work. Likewise, half $(49.74 \%)$ of the respondents agreed on psychological stress from work, $41.11 \%$ stated lack of time due to study while the least (14.21\%) reported that the main barrier was the presence of disease condition (Table 3).

\begin{tabular}{|c|c|c|c|}
\hline S.N. & Variables & n (\%) & n (\%) \\
\hline \multicolumn{4}{|c|}{ Screening Practice } \\
\hline 1. & Regular Physical Checkup annually $(\mathrm{n}=197)$ & $94(47.7)$ & $103(52.3)$ \\
\hline 2. & $\begin{array}{l}\text { Regular Breast Self-Examination } 5-7 \text { days after the start of men- } \\
\text { struation each month for pre-menopausal } \\
(\mathrm{n}=189)\end{array}$ & $100(52.92)$ & $89(47.08)$ \\
\hline 3. & $\begin{array}{l}\text { Regular Breast Self-Examination in a fixed day every month for } \\
\text { post-menopausal }(\mathrm{n}=8)\end{array}$ & $0(0.0)$ & $8(100.0)$ \\
\hline 4. & $\begin{array}{l}\text { Regular mammography every year for those who are } \geq 40 \text { years } \\
(\mathrm{n}=12)\end{array}$ & $3(25.0)$ & $9(75.0)$ \\
\hline 5. & $\begin{array}{l}\text { Regular Pap smear every three years for those } 21-65 \text { years } \\
(\mathrm{n}=175)\end{array}$ & $3(1.71)$ & $172(98.28)$ \\
\hline \multicolumn{4}{|c|}{ Vaccination Practice $(n=197)$} \\
\hline 6. & Hepatitis B & $125(63.5)$ & $72(36.54)$ \\
\hline 7. & Influenza & $3(1.5)$ & $194(98.47)$ \\
\hline 8. & Tetanus & $93(47.2)$ & $104(52.79)$ \\
\hline \multicolumn{4}{|c|}{ Habits $(n=197)$} \\
\hline 9. & Smoking Habits & $0(0.0)$ & $197(100.0)$ \\
\hline 10. & Alcohol consumption habits (Social Drinkers) & $154(78.2)$ & $43(21.8)$ \\
\hline \multicolumn{4}{|c|}{ Dietary Pattern $(n=197)$} \\
\hline 11. & Choose diet low in saturated fat and cholesterol routinely & $73(37.1)$ & $124(62.9)$ \\
\hline 12. & Avoid use of junk foods always & $74(37.6)$ & $123(62.4)$ \\
\hline 13. & Eat 3-5 servings of vegetables each day & $117(59.4)$ & $80(40.6)$ \\
\hline 14. & Eat 2-4 servings of fruits each day & $92(46.7)$ & $105(53.3)$ \\
\hline 15. & Eat 2-3 servings of milk/yogurt each day & $93(47.2)$ & $104(52.8)$ \\
\hline 16. & Eat 2-3 servings of meat, poultry, eggs, dried bean each day & $109(55.3)$ & $88(44.7)$ \\
\hline 17. & Eat 6-11 servings of carbohydrates each day & $111(56.3)$ & $86(43.7)$ \\
\hline 18. & Consume at least 8 glasses of water each day & $114(57.9)$ & $83(42.1)$ \\
\hline \multicolumn{4}{|c|}{ Exercise $(n=197)$} \\
\hline 19. & Perform 30 minute exercise at least 5 times/week & $51(25.9)$ & $146(74.1)$ \\
\hline \multicolumn{4}{|c|}{ Rest $(\mathrm{n}=197)$} \\
\hline 20. & Take enough sleep 6-8 hours/ day & $130(66.0)$ & $67(34.0)$ \\
\hline
\end{tabular}

\begin{tabular}{|lc|}
\hline \multicolumn{2}{|l|}{ Table 3. Current Health Maintenance Practices of respondents. } \\
\hline Barriers to Health maintenance Practices & n (\%) \\
Lack of time due to work & $160(81.21)$ \\
Psychological stress from work & $98(49.74)$ \\
Lack of time due to study & $81(41.11)$ \\
Lack of money & $57(28.93)$ \\
Lack of time due to children & $55(27.91)$ \\
Lack of support from family & $40(20.30)$ \\
Presence of disease condition & $28(14.21)$
\end{tabular}




\section{DISCUSSION}

Holistic care is a hallmark component of nursing practice that is centered on self-care however this practice is found to be very rare among nurses. ${ }^{11}$ Turkel \& Ray $^{12}$ has mentioned that a nurse who does not care for themselves cannot compassionately care others. Therefore, it is essential that nurses take care of themselves to be role models for the patients.

In our study, more than fifty percent $(61.4 \%)$ of nurses were found to be overweight which is more than the study finding of other studies. ${ }^{3,13,14}$ This could possibly be due to inclination of nurses towards the choice of easily available fast foods as lack of time was pointed as the major reason for not being able to cook healthy choice of foods by nurses in our study. The Center for Disease Control $^{8}$ recommends that all the health care workers get immunized against hepatitis B, Influenza, MMR, Varicella, DPT and meningococcal. However, the vaccination practices among nurses were found to be very poor in this study. The government in Nepal provides free vaccination to only children that too in only some selected ones such as BCG, DPT, polio, MMR. Other people including health care professionals have to pay for the vaccines if they want to take it. Besides, nurses might have ignored the vaccination practices as it is not mandatory in the organization they work for. This could possibly explain why nurses had so low percentage of vaccination practices in this study.

Most of the studies have not been able to assess the screening practices among nurses. Our study finding revealed that, of total 189 premenopausal participants, only half of them performed Breast Self-Examination (BSE) every 5-7 days of menstruation each month, while none of the menopausal participants were found to perform BSE. Our study finding resembles with the findings of the study conducted in Canada ${ }^{15}$ and Turkey ${ }^{16}$ where $53.3 \%$ and $52 \%$ of nurses reported to conduct regular Self breast examination respectively. However, study of Saudi $\mathrm{Arab}^{17}$ reported that more than two third: $(84.4 \%)$ of nurses performed BSE respectively. Our study finding is however, more than that of Nigerian study $^{18}$ and Study of Turkey ${ }^{19}$ where only $41.2 \%$ and $30.1 \%$ of nurses were found to practice BSE monthly respectively.

The American Cancer Society ${ }^{9}$ recommends that all women of age 40 years and above undergo yearly mammogram and all the women of age 21-64 years who are sexually active should have Pap smear test at least every three years for the early detection of cancer. In our study very nominal percentage of respondents eligible for mammography did it on a regular basis, though the figure is bigger than reported in other two Nigerian studies ${ }^{20,21}$ in which only $8 \%$ and $3.1 \%$ of eligible participants had performed mammogram respectively. However, in the study by Ozgur \& 1zzetin ${ }^{19} 34.9 \%$ performed mammogram which is more than in our study. Mammogram is considered as an expensive diagnostic procedure in Nepal. Besides, the detrimental consequence of repeated radiographic exposure $^{22,23}$ might have discouraged nurses to perform it regularly. Studies conducted in India ${ }^{24-26}$ have however reported more cervical screening practices than in our study ranging from $11.6 \%$ to $18.4 \%$.

The focus on living a healthier lifestyle is applicable not only to patients, but nurses as well. ${ }^{27}$ In our study only $37.1 \%$ of nurses were found to choose the diet low in saturated fat on a routine basis. This is consistent to a study conducted in Hong Kong where more than $60 \%$ of the nurses had unhealthy eating habits. ${ }^{27}$ On the contrary, another study ${ }^{28}$ mentioned that $73 \%$ of nurses chose healthy dietary habits. In the study by Zapka et al ${ }^{29} 18.3 \%$ of nurses consumed fruits while $34 \%$ consumed vegetables routinely which are less than our study finding (59.4\%). Interestingly, more than half $(53.8 \%)$ of the nurses reported that they did not eat regular meals. ${ }^{30}$ Lack of time, busy life, high cost of healthy foods were some of the barrier why nurses did not have regular meals in the study by Nahm et al. ${ }^{30}$ Therefore, nurses in our and other studies have failed to maintained the dietary practice that the American Heart Association ${ }^{6}$ and $\mathrm{WHO}^{10}$ recommended which stated that an adult should have 6-8 servings of wholegrain per day, 45 servings of vegetables and fruits per day, less than $6 \mathrm{oz}$ of lean meat, seafood and poultry per day; 4-5 servings of nuts, seed and legumes per week.

The World Health Organization ${ }^{10}$ has recommended 30 minutes of moderate-intensity activity 5 times per week for 18- 64 years healthy individuals. Similarly, American Heart Association suggests at least 150 minutes per week of moderate exercise or 75 minutes per week of vigorous exercise $^{6}$ and 7-9 hours of sleep. ${ }^{6,10,31}$ In a study conducted in Finland ${ }^{2}$ only $25.5 \%$ of respondents were found to exercise more than four hours in a 
week. Our study finding is comparable to this study while contradicts with the findings of a Canadian ${ }^{15}$ and US based study ${ }^{30}$ in which nearly half of the nurses were found to be physically active. There could be various reasons for not performing exercise regularly even though nurses were aware of its importance. The main reasons given in our study were: lack of time due to work, psychological stress and lack of time due to study.

A day time power nap has been proved to reenergize individuals so that nurses can perform better and engage themselves in healthy behaviors. ${ }^{32}$ More than half of the nurses in our study fulfilled the recommended 8 hours of sleep. ${ }^{6,10}$ However, only $25 \%$ of the nurses mentioned that they slept enough in a study by Chow \& Kelischuk. ${ }^{3}$ Busy schedule and incompatible work schedules were the main reasons why nurses did not get enough time to sleep in the study by Chow \& Kelischuk. ${ }^{3}$

Smoking and alcohol consumption both are directly linked to cause negative impact on our health. Our study finding share similarities with two other studies, ${ }^{3,} 33$ in that majority of nurses were occasional drinkers. In contrast, study by Ratner et $\mathrm{al}^{13}$ and Lehman ${ }^{2}$ reported that $6.9 \%$ and $19.7 \%$ of respondents were a risk alcohol consumer. Smoking habit was not exhibited by any of the nurses in this study. However, few other studies reported quite noticeable smoking percentage of nurses ranging from $14.82 \%$ to $42.9 \%{ }^{2,3,15,30,33,34}$ In our context,

\section{REFERENCES}

1. American Academy of Pediatrics, Introduction to health promotion and health maintenance. http:// health.prenhall.com/ballpediatric/pdf/Ball_ch07.pdf. [Link]

2. Lehman F, Lindeman KV, Klewer J, Kugler J. BMI, physical inactivity, cigarette and alcohol consumption in female nursing students: a 5-year comparison. BMC Med Educ. 2014; 14: 82. [BMC]

3. Chow J, Kalischuk RG. Self-care for caring practice: Student Nurses' Perspectives. Int J Human Caring. 2008; 12 (3): 31-37. [Link]

4. American Nurses Association, Healthy Nurse, Healthy Nation. http://www.nursingworld.org/healthynurse. [Link]

5. Reed D. Healthy Eating for Healthy Nurses: Nutrition Basics to Promote Health for Nurses and Patients. The Online J Issues Nurs. 2014; 19 (3): Manuscript 7. [Link]

6. American Heart Association. American Heart Association Recommendations for Physical Activity in Adults: USA, 2015 .http://www.heart.org/HEARTORG/ GettingHealthy/PhysicalActivity/FitnessBasics/AmericanHeart-Association-Recommendations-for-Physical-Activity -in-2Adults_UCM_307976_Article.jsp\#.VpeiJv197IU.

7. World Health Organization. Appropriate body-mass index for Asian populations and its implications for policy and intervention strategies. Lancet. 2004; 363 (9403): 157-63. https://www.ncbi.nlm.nih.gov/pubmed/14726171 smoking by female is not socially acceptable. Besides, nurses are generally aware of the consequences of smoking and are considered as the role model for public. These could be the possible reasons why smoking habit was not found among participants.

\section{CONCLUSION}

The study finding reveals that nurses did not have a good screening, dietary, exercise and vaccination practices. Lack of time, work overload, psychological stress from work were the main barriers for maintaining health among nurses. Provision of regular health screening, encouragement of the staffs to maintain healthy lifestyle and availability of infrastructure for exercise within the organization could be some of the initiatives to be taken by the employer. Selfawareness regarding one's own health and implementation of healthy practices are the other aspects that nurses need to focus on. Further, research focusing this aspect could be conducted at larger scale using longitudinal study approach to identify the predictors of health of the nurses. A national survey to assess health maintenance practice could also be of paramount benefit to explore the current status.

\section{ACKNOWLEDGEMENT}

Special thanks to all the nurses of Nepal Medical College Teaching Hospital without whom this study would not have been possible.

8. Centers for Disease Control and Prevention. Cervical Cancer. Atlanta: Centers for Disease Control and Prevention, US Dept of Health and Human Services, 2014. h t t p s://www.cdc.gov/cancer/cervical/pdf/ Cervical_facts.pdf. [Link]

9. American Cancer Society Guidelines for the Early Detection of Cancer, 2017. https://www.cancer.org/healthy/ find-cancer-early/cancer-screening-guidelines/americancancer-society-guidelines-for-the-early-detection-ofcancer.html. [Link]

10. World Health Organization, Global Strategy on Diet, Physical Activity and Health 2014. http://www.who.int/ dietphysicalactivity/factsheet_adultsen/.

11. McElligott D, Capitulo KL, Morris DL, Click ER. The effect of a holistic program on health promoting behaviors in hospital registered nurses. J Holist Nurs. 2010; 28 (3): 175-83. [Link]

12. Turkel MC, Ray MA. Creating a caring practice environment through self-renewal. Nurs Adm Quarterly. 2004; 28 (4): 249-54. https://www.ncbi.nlm.nih.gov/ pubmed $/ 15612398$

13. Kihye H. Job stress and work schedules in relation to nurses obesity. J Nurs Adm. 2011; 41(11): 488-95. https:// www.ncbi.nlm.nih.gov/pubmed/22033319

14. Miller SK, Alpert PT, Cross CL. Overweight and obesity in nurses, advanced practice nurses, and nurse educators. J Am Acad Nurse Pract. 2008; 20 (5): 249-65. [Link] 


\section{Shrestha et al. Health Maintenance Practices among Nurses of a Tertiary Level Hospital of Nepal}

15. Ratner PA, Sawatzky R. Health Status, preventive behavior and risk factors among female nurses. Statistics Canada, Report 2009; 20 (3). [Link]

16. Erten G, Kocer A. Breast Self-examination among nurses and midwives in Odemis health district in Turkey. Indian $\mathrm{J}$ Cancer. 2009; 46(3): 208-13. [Link]

17. Sreedharan J, Muttappallymyalil M, Venkatramana, M, Thomas M. Breast self-examination: knowledge and practice among nurses in United Arab Emirates. Asian Pac J Cancer Prev. 2010; 11(3): 651-54. [Link]

18. Yakabu AA, Gadanya MA, Sheshe AA. Knowledge, attitude, and practice of breast self-examination among female nurses in Aminu Kano teaching hospital, Kano, Nigeria. Niger J Basic and Clinical Sci. 2014; 11 (2): 8588. [Link]

19. Ozgur AE, Izzettin T. Knowledge, Attitudes, and Behaviors about Breast Self-Examination and Mammography among Female Primary Healthcare Workers in Diyarbakır, Turkey. BioMed Research Int. 2016; 2016: 1-6. [Link]

20. Odusanya OO, Tayo OO. Breast cancer knowledge, attitudes and practice among nurses in Lagos, Nigeria. Acta Oncol. 2001; 40(7): 844-48. https:// www.ncbi.nlm.nih.gov/pubmed/11859984

21. Adenike AO, Vivian OO. Knowledge, attitudes and practice of breast cancer screening among female health workers in a Nigerian urban city. BMC Cancer. 2009; 29 (203). [Link]

22. Løberg M, Lousdal MS, Bretthauer M, Mette K. Benefits and harms of mammography screening. Breast Cancer Res. 2015; 17(1): 1-12. [Link]

23. Jørgensen KJ. Mammography Screening Benefits, harms and informed choice. Dan Med J .2013; 60 (4): 1-26. https://www.ncbi.nlm.nih.gov/pubmed/23651722

24. Hafizur R, Sumit K. Knowledge, attitudes and practice toward cervical cancer screening among Sikkimese nursing staff in India. Indian J Med Paediatr Oncol. 2015; 36(2): 105-10. [Link]

25. Thippeveeranna C, Mohan SS, Singh LR, Singh NN. Knowledge, attitude and practice of the pap smear as a screening procedure among nurses in a tertiary hospital in north eastern India. Asian Pac J Cancer Prev. 2013; 14(2): 849-52. [Link]

26. Anantharaman VV, Sudharshini S, Chitra A. A crosssectional study on knowledge, attitude, and practice on cervical cancer and screening among female health care providers of Chennai corporation. J Acad Med Sci. 2012; 2 (4): 124-128. [Link]

27. Speron KG. Designing Exercise and Nutrition Programs to Promote Normal Weight Maintenance for Nurses. Online J Nurs Article. 2014; 25(5): 64-71. [Link]

28. Connolly MA, Gulanick M, Holm VK. Health practices of critical care nurses: are these nurses good role models for patients. Am J Crit Care. 1997; 6(4): 261-66. https:// www.ncbi.nlm.nih.gov/pubmed/9215422

29. Zapka JM, Lemon SC, Magner RP, Hale J. Lifestyle behaviours and weight among hospital-based nurses. J Nurs Manag. 2009; 17(7): 853-60. [Link]

30. Nahm ES, Warren J, Zhu S, An M, Brown J. Nurses' selfcare behaviors related to weight and stress. Nurs Outlook. 2012; 60 (5): e23-e31. https://www.ncbi.nlm.nih.gov/ pubmed/22770679

31. Hirshkowitz M, Whiton K, Albert SM, Alessi C, Bruni O, DonCarlos L, et al. National Sleep Foundation's updated sleep duration recommendations: final report. Sleep Health. 2015; 1(4): 235-45. https://www.ncbi.nlm.nih.gov/ pubmed/29073398

32. Han K, Trinkoff AM, Storr CL, Geiger-Brown, Jeanna. Job Stress and Work Schedules in Relation to Nurse Obesity. J Nurs Adm. 2011; 41(11): 488-95. https:// www.ncbi.nlm.nih.gov/pubmed/22033319

33. Fernandes JC, Portela LF, Rotenberg L, Griep RH. Working hours and health behaviour among nurses at public hospitals. Rev Latino-Am Enfermagem. 2013; 21 (5): 1104-11. [Link]

34. Adamek R, Stoczynska J, Maksymiuk T, Zysnarska M, Gromadecka-Sutkiewicz M, Kara I, Kalupa W. Prevalence of tobacco smoking among nurses and the awareness of harmfulness of smoking habit. PrzeglLek.2012;69(10):9672. https://www.ncbi.nlm.nih.gov/pubmed/23421072 